\title{
CONSUMO Y PRÁCTICAS SOCIALES "OCULTAS": LA PROSTITUCIÓN
}

Fco. Javier Rubio Arribas

Sociólogo, Orientador e Intermediador Laboral, Madrid

http://dx.doi.org/10.5209/rev_NOMA.2012.v34.n2.40740

\begin{abstract}
Resumen.- Desde el punto de vista psicosociológico, las personas que ejercen prostitución constituyen un grupo heterogéneo con importantes diferencias en sus reacciones y en el ejercicio de esta profesión. Los principales actores sociales son tres: las personas que ejercen prostitución (mayoritariamente mujeres), los clientes y los grupos de presión (mafias; redes y proxenetas). El estigma social se hace patente sobretodo en algunas de las modalidades de ejercicio, como es en el caso de la prostitución de calle y de algunos clubes (en los de menor categoría) en los que ejercen principalmente mujeres con mayor riesgo de exclusión social. El resto de modalidades (clubes de alto standing; prostitución de lujo; pisos; servicios virtuales, etcétera.), caracterizados por una mayor privacidad, ocultamiento y una doble vida escapan a este estigma. La prostitución se ejerce por dinero. Es decir, por la misma razón por la que se lleva a cabo cualquier actividad socialmente desvalorizada. Por tanto la necesidad de acceder a rentas está presente en la mayoría de los itinerarios de acceso a la prostitución.
\end{abstract}

Palabras clave.- prostitución; explotación sexual; los clientes de la prostitución; trabajadoras del sexo; nuevos perfiles de las ejercientes; estigma de la prostituta.

Abstract.- From the psychosocial point of view, people who exercise prostitution constitute a heterogeneous group with important differences in their reactions and in the practices of this profession. There are three main social actors: people who exercise the prostitution (mostly women), the clients and pressure groups (mafias, networks and procurers). Social stigma becomes evident, above all in some types of exercises, such as street prostitution, and some clubs (lesser category) where most of the women have a high risk of social exclusion. The rest of the modalities (club of high standing, luxury prostitution, flats, virtual services, etc) characterize by a greater privacy, concealment and a double life escape this stigma. Prostitution is done for money. That is, for the same reason that any socially devalued activity is carry out. So, the need to obtain incomes is present in most of the paths that lead to prostitution.

Keywords.- prostitution, sexual exploitation, consumption of prostitution, clients of prostitution, sex workers, new profiles of workers, social stigma of the prostitute.

SUMARIO: Introducción | Enfoques sociolegales sobre la prostitución | Sobre el concepto de prostitución | Motivos para ejercer | El rol de prostituta: las "principales actrices" | Aspectos sociológicos del lado oscuro de la prostitución: los grupos de explotación | Aspectos psicosociológicos del cliente de prostitución: el consumidor | Alternativas al mercado del sexo | Conclusiones | Datos estadísticos sobre prostitución y tráfico.

"Solo pones tu cuerpo y ya está" (Mujer prostituta en ejercicio).

\section{Introducción}

A la hora de abordar el tema de la prostitución, el sociólogo que lo está escribiendo, tiene claro que está totalmente en desacuerdo ylo contra la prostitución infantil (sea cual sea la forma/modo) y contra la prostitución ejercida bajo coacción, violencia o régimen de esclavitud. Y mi deseo para quienes trabajan en ello, que sea siempre, ejercida por mayores de edad, con 
soberana voluntad y con derechos en su ejercicio. Además, que este ejercicio profesional lo sea en las "mejores" condiciones de higiene y seguridad posible -que con voluntad se podría-. Con esto no estoy diciendo que sea ni lo mejor ni lo peor y si una profesión que como tal debería tener al menos condiciones semejantes a las que tenemos el resto de trabajadores y trabajadoras (impuestos, seguridad social y días de vacaciones, es decir, cierta regularización sociolaboral).

En segundo lugar, se puede afirmar -sin miedo a equivocarse-, que el tema de la prostitución es un fenómeno transnacional y globalizado, ya que no se puede considerar un fenómeno local o nacional sino uno internacional. Donde los actores implicados pertenecen a diversas esferas, tanto la mujer prostituta y sus clientes ${ }^{1}$, pasando por los actores que tienen algún tipo de relación directa e indirecta con la actividad, y por último, los gobiernos y organismos internacionales.

\section{Enfoques sociolegales sobre la prostitución ${ }^{2}$}

Es un fenómeno complejo y que afecta a una realidad con múltiples esferas (como los cristales de un calidoscopio ${ }^{3)}$ y no se puede contar con una perspectiva única en su tratamiento. Esta actividad y de lo que ella está envuelta, siempre se rodeada de polémica y lo es tanto, de su enfoque social, jurídico como moral ${ }^{4}$.

Existen varias estrategias para abordar el tema de la prostitución, y que va desde la penalización/prohibición hasta la consideración de su ejercicio y/o práctica como un trabajo más que debería ser legalizado.

A continuación muestro brevemente estas posturas o tendencias (y que no sólo se dan en España sino en determinados países europeos), estas son:

\footnotetext{
${ }^{1}$ Se puede consultar el siguiente estudio cualitativo: "La voz de las mujeres que ejercen la prostitución" coordinado por I. Serra del Institut Universitari d'Estudis de la Dona de la Universitat de València, en colaboración con la Universidad Jaume I y la Fundación ISONOMIA entre otras. Valencia. Para la que se realizaron 23 entrevistas en profundidad.

${ }^{2}$ Sería interesante consultar el Informe que se presentó en el Congreso de los Diputados, dentro de la Comisión Mixta de los Derechos de la Mujer y de la Igualdad de Oportunidades del Congreso de los Diputados. Estudio de la prostitución en España: La prostitución en el mercado económico. Madrid, 11 de Julio de 2006, Congreso de los Diputados. Por D. Borja Ventura, Periodista. Mail: borja.ventura@gmail.com. URL: http://blogs.periodistadigital.com/blogdenotas.php.

${ }^{3}$ Según el Diccionario de la Lengua Española, calidoscopio es un: "tubo ennegrecido interiormente, que encierra dos o tres espejos inclinados y en un extremo dos láminas de vidrio, entre las cuales hay varios objetos de figura irregular, cuyas imágenes se ven multiplicadas simétricamente al ir volteando el tubo, a la vez que se mira por el extremo opuesto". Diccionario de la Lengua Española. Real Academia Española. Vigésima Primera Edición. Tomo I. Madrid, 1992. Página 365.

${ }^{4}$ Desde el punto de vista jurídico, sería interesante consultar el siguiente artículo: "la prostitución como trabajo autónomo" de Glòri Poyatos i Matas, abogada y profesora asociada de la UdG (Universidad de Girona), Se puede consultar en la web: http://www.jpdsocial.org/Articles/5.2PoyatosMataPonencia.pdf.
} 
- La postura abolicionista tiende a considerar la prostitución como un atentado contra la dignidad de la mujer y por tanto, niega toda posibilidad de legalización, ya que llevaría a perpetuar esta injusticia (reconoce su existencia y lucha por su erradicación). Esta postura surgió en el siglo XIX en Gran Bretaña, sobre la idea de que la prostitución es una violación de los Derechos Humanos y, como tal, no puede ser tolerada desde el punto de vista social, moral y jurídico.

- La postura prohibicionista se basa en la represión penal del ejercicio de la prostitución, castigando tanto a quien la ejerce como al cliente que acude en busca de algún tipo de servicio sexual (la que prohíbe y castiga). Esta postura no permite el reconocimiento de la actividad de la prostitución y, por consiguiente, el ejercicio se persigue policial y judicialmente.

- La postura reglamentarista, basada en un rechazo moral de la prostitución pero su perspectiva es diferente, al considerar que es un mal moral inevitable y que, en esta medida, es necesario aceptarla y regularla para evitar la clandestinidad en la que es ejercida (el que tolera y reglamenta la actividad). Bajo esta tendencia, sería el Estado quien debería controlar esta actividad, y por tanto, debería imponer una serie de controles de orden público, conducentes a la ordenación de la prostitución en sus diversos aspectos, de tal manera, que se garantice el ejercicio de los servicios sexuales en las mejores condiciones sanitarias posibles.

- La postura legalista considera que la prostitución debe ser regulada en su totalidad como una actividad laboral más, otorgando a las trabajadoras de la industria del sexo los mismos derechos y la misma protección social y jurídica que al resto de los trabajadores y trabajadoras.

- Una postura alternativa es la mantenida por la profesora del Instituto de Estudios Sociales de Holanda, Tranhdam Truong ${ }^{5}$. Esta postura propone una superación del actual antagonismo abolicionismo contra regulacionismo, en base a esta posición: regulación hacia la abolición. De esta forma, se reconoce la regulación de la prostitución para fortalecer la posición de las mujeres frente a la violencia u opresión que padecen en el ejercicio de la actividad. Según señala la autora, la regulación tiene como estrategia la abolición de la prostitución por medio de un cambio estructural mucho más profundo, y que debería afectar tanto a las esferas sociales, como a las económicas y jurídicas.

\footnotetext{
${ }^{5}$ Truonhg Thanh-Dam. Gender, International Migration and Social Reproduction: Implications for Theory, Policy, Research and Networking. Asian and Pacific Migration Journal, vol.5, $\mathrm{n}^{\circ} 1$; 1996.
} 


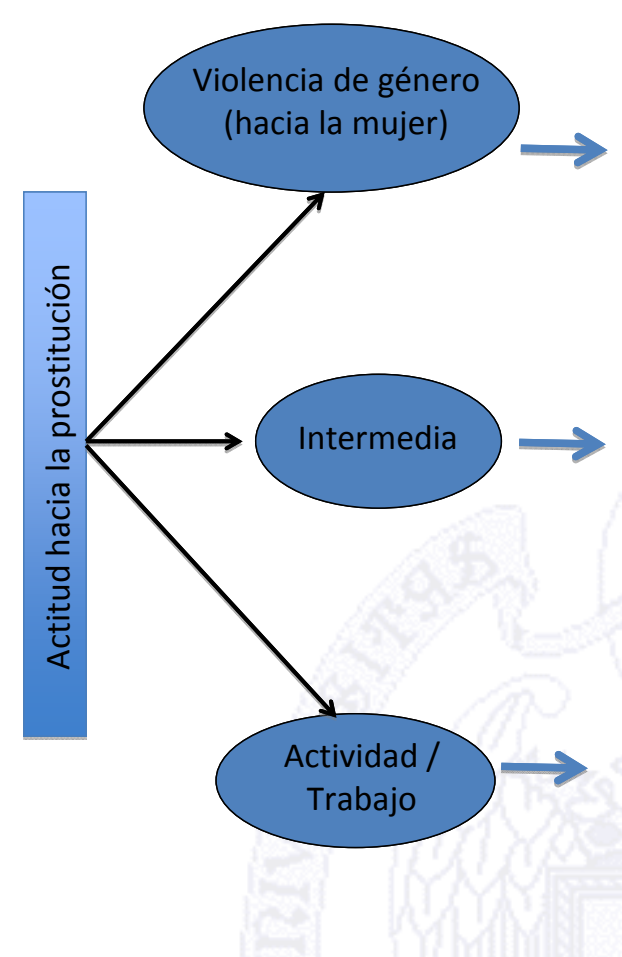

Fuente: Elaboración propia. Madrid, 2012.
Prohibición.

No se puede ni debe regular.

$\square$ Coherencia--- $\rightarrow$ castigo al consumo (delito).

G Sin protección.

Alteración del orden público: inseguridad; robos; violencia; drogas.....

Desregularizar: "prostitución sumergida".

Ejemplos: leyes escandinavas (Suecia; Noruega e Islandia).
Imposibilidad social de erradicarla. ACEPTACIÓN No sancionar el consumo.

Irregular: "no regulada".

Regular sus condiciones laborales: protección a la mujer prostituta.

Lucha contra el tráfico y explotación de la mujer.

Aceptar la regulación.

REGULACIÓN

No prohibición.

Permitir su consumo.

Consideración de actividad y/o trabajo: asalariadas y autónomas (cotización a Seguridad Social y pensiones).

$\square$ Con protección sociolaboral.

"Ejercicio con derechos".

Ejemplo: Holanda.

\section{Sobre el concepto de prostitución}

Desde el punto de vista conceptual, se puede entender por prostitución: «un conjunto de actividades en las que se establece una relación comercial y en las que se intercambia sexo por dinero» ${ }^{6}$.

"- Por eso pienso y digo que la prostitución debe ser una transacción, un acuerdo entre la persona que pide el servicio y la que lo da". [EP Colectivo: Mujer transexual que ejerce la prostitución en la calle] ${ }^{7}$

\footnotetext{
${ }^{6}$ Solana Ruiz -doctor en Filosofía y profesor de Antropología- define prostitución como: «la actividad a la que se dedica la persona que, a cambio de dinero u otros bienes, presta a otras servicios sexuales que implican contacto carnal. Las condiciones en que se realiza el intercambio material puede depender de diversos factores (sociales, políticos, que intercedan mediadores, personales...)». Extraído de la página web, http://www.colectivohetaira.org/fracor20704.html.

${ }^{7}$ Información extraída de mi estudio cualitativo: "Proyecto de investigación-acción sobre buenas prácticas de inserción por lo económico de personas con especiales dificultades en el mercado laboral madrileño". Realizado en el año 2006 para la Secretaria de Política Social e Igualdad de Comisiones Obreras de Madrid y, la Dirección General de Servicios Sociales de la Comunidad de Madrid. Dirigido, realizado y redactado por Fco. Javier Rubio Arribas. Estudio no publicado. La investigación se basó en una aproximación al fenómeno de la exclusión social y laboral de las personas que tienen especiales dificultades de acceso al mercado de trabajo, desde el punto de vista de las opiniones, imágenes y representaciones sociales, desde los discursos de las personas que trabajan con estos ciudadanos y ciudadanas y con el de las
} 
Sin embargo, hoy en día hay infinidad de actividades comerciales, que a pesar, de existir un intercambio de dinero por alguna actividad relacionada con el sexo: casas de masajes; web's eróticas; anuncios de contactos y/o amistades; venta de lencería erótica, etcétera, no cuentan -desde el punto de vista socialcomo prostitución. Existe un nutrido conjunto de actividades comerciales como observamos- reguladas o no, en las que el sexo es un componente primordial, cuando no imprescindible.

Hablando llanamente, la prostitución es sexo por dinero ${ }^{8}$. La definición jurídica más antigua, procedente del Codex Justinianus del Bajo Imperio Romano define a una prostituta (meretrix) como una mujer que ofrece servicios sexuales públicamente (palam omnibus) por dinero (pecunia accepta) y sin distinción (sine delectu). La definición de la palabra y —su empleo- está vinculada a cada época y a cada cultura.

La prostitución es una actividad laboral no reglada en España, pero visible. Algunos expertos hablan que existen unas 300.000 personas dedicadas a la prostitución.

Ahora bien, sin entrar en mayores debates sobre el tema de la prostitución -es decir, sobre tener un posicionamiento u otro al respecto-, lo que sí que debo hacer es desde este artículo, es concebir a las mujeres prostitutas y exprostitutas con dignidad y con capacidad para decidir sobre sí mismas y sobre las condiciones de vida, aunque muchas veces, éstas sean difíciles. Porque son mujeres que intentan «vivir/sobrevivin» en un mundo lleno de multitud de desigualdades y además de todo tipo (económicas; regionales; étnicas; culturales; de género; según su transexualidad; su adicción, etcétera), y que buscan mejorar dentro de la situación que les ha tocado vivir.

Por esta razón, no deberíamos considerar a las mujeres que ejercen la prostitución como víctimas ${ }^{9}$-por lo menos a la mayoría-. Lo que no significa que desde estas líneas no se reconozca la existencia de redes delictivas que obligan a mujeres y niñas a prostituirse, en régimen de esclavitud. Estas situaciones allí donde se produzcan deben ser denunciadas porque además, existen los medios legales suficientes para combatirlas.

personas que se encuentran en zonas de exclusión, como son: «personas con enfermedad mental; parados y paradas de larga duración, mujeres mayores de 45 años; personas que han sufrido violencia de género; personas que han ejercido o ejercen prostitución; personas con barreras lingüísticas -personas inmigrantes-; personas sin hogar; personas transexuales; jóvenes; personas exdrogodependientes y con VIH-SIDA y personas que han salido de prisión».

${ }^{8}$ La prostitución se ejerce por dinero (prostitución económica). La necesidad de acceder a rentas está presente en la mayoría de los itinerarios de acceso a la prostitución. La constricción económica siempre está presente. "prostitución. (Del lat. prostitutǐo, -ōnis). 1. f. Acción y efecto de prostituir. 2. f. Actividad a la que se dedica quien mantiene relaciones sexuales con otras personas, a cambio de dinero". Definición extraída del Diccionario de la Real Academia Española de la Lengua.

9 Considerando «víctima» a toda aquella persona que ejerce la prostitución sometida a la disciplina de redes organizadas o bajo una «relación laboral» con terceras personas (independientemente que denuncien o no). Y según la Guardia Civil, técnicamente solo cabría denominar «víctima» a la persona que presenta denuncia. 
Para el caso de aquellas mujeres que actualmente están ejerciendo prostitución, preferimos acuñar el término: mujer que ejerce prostitución o bien, mujer que ha ejercido prostitución. De este hecho, se resalta el concepto mujer, el sujeto por encima del ejercicio u oficio. Porque en el fondo son ampliamente las mujeres las que se encuentran en este sector o las que intentan dejarlo. Son ellas las que ejercen esta acción y por último, este término está abierto porque hay mujeres que lo ejercen libremente y otras por condicionamientos y presiones externas.

Las personas que ejercen en la actualidad, se consideran y/o perciben así mismas, como profesionales:

"- Sí, mas de lo que la gente cree, por eso a veces te dicen ¿eres profesional? Mas de lo que la gente lo cree. Que en nuestro caso a lo que nos toca, el sexo. El sexo lo vemos como un instrumento de ganarse el dinero. Es como aquella persona que le gusta cocinar, le gusta cocinar, le gusta cocinar, hala, yo me voy a un restaurante a emplearme para cocinar muchos platos. $Y$ para aprender más. Que nada tiene que nuestra situación y la situación de muchas no tiene nada que ver con lo que... con el circo mediático que se montan a veces los políticos, las mafias y...". [EP Colectivo: Mujer transexual que ejerce la prostitución en la calle]

Reivindican esta actividad o ejercicio como un oficio (Hetaira ${ }^{10}$ ) profesionalizado aunque vinculado con el sexo, para que socialmente no sea tan estigmatizado como lo está actualmente.

\section{Motivos para ejercer}

En las entrevistas -que realicé para mi estudio sociológico- aparecieron los siguientes motivos por los que una persona puede comenzar a ejercer prostitución y, éstos son:

- El económico. Al pertenecer a países donde existe un bajo nivel de renta y/o carencia de bienestar sociolaboral. Además, en sus países de origen tienen elevadas tasas de desempleo y muchas personas han emigrado. Buscando una nueva alternativa a la situación que viven en sus países de origen.

"- En el caso de las mujeres yo creo que en el $90 \%$ de los casos o me atrevería a afirmar que hasta en el $95 \%$ de los casos estamos hablando de inmigrantes con grandes necesidades económicas en sus países de origen". [EP Profesionales de Inserción: Mujeres que ejerce la prostitución]

- Por tener cargas familiares directas (hijos, padres y hermanos) e indirectos (otros familiares de segunda generación, como son primos). Bien que se encuentren en nuestro país, bien en su país de origen.

\footnotetext{
${ }^{10}$ En la antigua Grecia -Hetaira- era la cortesana y a veces, de elevada consideración social.
} 
"- Tengo tres niños, soy madre soltera. En Venezuela las cosas no marchan como deberían marchar. Con un sueldo mínimo y no me llegaba. Lo que te hagas en una noche, puede ser quinientos o mil, se lo quedan las chicas totalmente ellas." [EP Colectivo: Mujer inmigrante -Venezuela- que ejerce la prostitución en local]

- El engaño, por el tráfico de personas. Que como veremos en otro punto de este artículo -sociología del lado oscuro de la prostitución-, este hecho es el peor de los motivos para salir de su país de origen.

- Una adicción como es la droga. Es decir, que primero fue consumidora y el incremento en el consumo de droga, le hizo necesitar tener mayores niveles de ingresos económicos. Cuando sus recursos económicos disminuyeron, se le cruzó el ejercicio de la prostitución y acabó en este mundo.

“- En mí caso no fue así pues vengo de una familia de clase media-alta, he cursado estudios, llevaba la contabilidad del taller de mi padre, tiene talleres de coches, sólo que quizás en mi camino se cruzaron personas que no debía haber conocido y me fui introduciendo en el mundo de la droga, y bueno, pues con el tiempo tienes una total dependencia de la sustancia, en cambio se cruzaron en mi camino personas que trabajaban en saunas pues por la zona de... que yo iba todos los días a buscarlos, los coches te paraban, yo no trabajo, hasta que un día te hace falta dinero y dices bueno, pues hoy si me paran me meto, y asi me fui introduciendo ejerciendo prostitución". [EP Colectivo: Mujer que ejerció prostitución]

\section{- Por una decisión propia y voluntaria.}

"- Yo tengo muchos años. Es una de las opciones que se te presentan, hay muchas personas que lo pensamos de una manera fría, si soy capaz de pasármela bien, pues acá con esta actividad, me gano unos dinerillos, que es lo mismo que voy a hacer. Lo mismo voy hacer, la diferencia es que acá ya me lo tomo con seriedad, o sea nuestro trabajo nos lo tomamos con seriedad". [EP Colectivo: Mujer transexual que ejerce prostitución]

En mi estudio encontré que muchas de las mujeres se encuentran sin recursos personales, sociales y económicos ${ }^{11}$. Y que debido a una situación personal de desempoderamiento eligen ( $y / 0$ se ven forzadas) ejercer la prostitución.

Para concluir este apartado y según el Colectivo Hetaira:

"Las mujeres no suelen dedicarse a esta tarea porque les agrade, ni porque están presionadas o amenazadas físicamente, sino simplemente porque no

\footnotetext{
${ }^{11}$ Entendiendo por recursos personales y sociales las actitudes y competencias personales relativas a autoestima; asertividad; seguridad personal; visión de futuro; la capacidad para proyectar y conseguir objetivos que promuevan bienestar y autorrealización; obtención de formación; su experiencia laboral previa; en el caso de personas extranjeras, la situación regularizada respecto a su inmigración, etcétera.
} 
tienen a su disposición otras actividades que les resulten más convenientes, desde el punto de vista de la relación ingresos/tiempo de trabajo. Además, suele ser la opción preferente para personas que tiene problemas de papeles (inmigrantes sin permiso de residencia) o necesidades económicas abultadas".

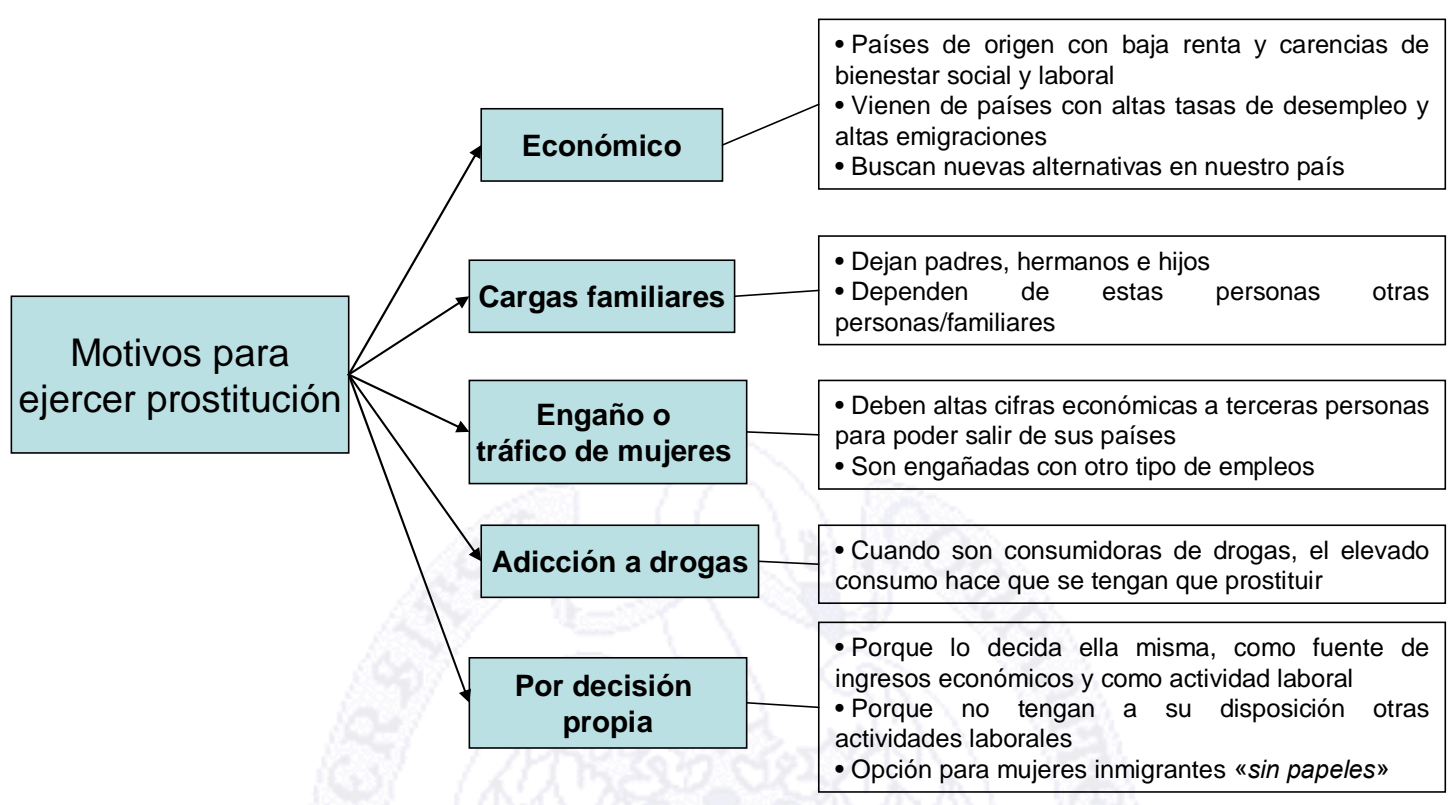

\section{El rol de prostituta: las "principales actrices"}

La prostitución no es ajena a los grandes cambios sociales. A pesar de tratarse de un tema que ha sido debatido en reiteradas ocasiones y en diferentes foros -incluida las Cortes Generales-, no se llega a un acuerdo. Ahora bien, resultaría conveniente regularizar un negocio que genera alrededor de veinte mil millones de euros al año y sigue siendo una tapadera para el blanqueo de capitales. Sin un respaldo legal adecuado el problema parece no solventarse.

En la actualidad no podemos relacionar al total de las mujeres que ejercen la prostitución con la exclusión social, ya que además de las formas "tradicionales del ejercicio"12 están apareciendo otras formas nuevas de prostituirse, sobre todo vinculadas con las nuevas tecnologías -como son Internet; la televisión a través de cable; teléfonos eróticos; anuncios público y publicables en la prensa; servicios realizados en domicilios particulares y en hoteles- $y$, que son realizadas bajo unas condiciones que hacen, que no se les pueda considerar que estas mujeres sean excluidas sociales.

Ahora bien, tal y como nos mostraba un informe de EDIS ${ }^{13}$, no podemos hablar de "colectivo", sino: "de un abanico amplio de mujeres, de personas (no todas son mujeres biológicas), que tienen como rasgo compartido el ejercicio de la

\footnotetext{
${ }^{12}$ La calle, plazas o locales. Estas mujeres a parte de su condición como prostituta ejerciente, tiene una alta vulnerabilidad y está más propensa a padecer situaciones de exclusión social.

${ }^{13}$ Estudio realizado y titulado: realidad Social de las mujeres sin techo, prostitutas, exreclusas y drogodependientes en España. Instituto de la Mujer y realizado por el Equipo de Investigación Sociológica EDIS, SA. Madrid, 2005.
} 
prostitución como manera de ganarse la vida"14. Por tanto, es una realidad sociológica heterogénea (caleidoscópica), con muchas formas y características, habiendo distintas tipologías de mujer prostituta. No es lo mismo ejercerla en un lugar que en otro (no es lo mismo en la calle, que en un local, que en domicilio, que en un hotel).

Las personas dedicadas al ejercicio de la prostitución, tienen un rasgo social común, son personas altamente estigmatizadas -desde el punto de vista social-. También hay que decir, que el estigma funciona de forma diferente si quien mira es una mujer o un hombre. Independientemente de esto, hay un juicio moral sobre el ejercicio de la prostitución. Cuando se encuentran presentes en sus espacios públicos, con frecuencia reciben insultos, vejaciones que dañan su autoconcepto como personas y como mujeres. Aunque llegan a reconocer, que con el tiempo, se les produce una cierta impermeabilidad hacia esta estigmatización social.

Son personas que viven una cierta "esquizofrenia" al tener que mantener una doble vida: vivencia sociofamiliar lo más normalizada posible y por otra, el ejercicio de la prostitución. Y en el centro el ocultamiento de esta actividad - la forma en cómo se ganan la vida- a la familia, a los conocidos, a los vecinos, etcétera. No son muchas las mujeres prostitutas que en su entorno más cercano y personal saben de esta actividad.

\section{Aspectos sociológicos del lado oscuro de la prostitución: los grupos de explotación}

En este apartado se analiza el lado oscuro de la prostitución, es decir, "los $a_{m o s}{ }^{15}$ de la misma". Nos estamos refiriendo a los grupos que la controlan: Mafias y Redes de explotación y de forma individual, el proxeneta (y/o chulo). Son quienes controlan actualmente el mercado y la distribución de la oferta. Da lo mismo la forma, grupal o individual, tratan a las mujeres como mercancía, como esclavas. Por tanto, utilizan métodos muy violentos para someterlas: violencia extrema; venta de las mujeres; muerte o graves lesiones; magia negra; secuestros.... Etcétera. Convierten a las mujeres en esclavas: "dejando de ser sujetos soberanos de su voluntad, y despojadas de todo derecho ciudadano".

Para hacer referencia al Tráfico de Seres Humanos (a partir de ahora TSH), utilizaremos la definición que aparece en la «Convención de Naciones unidas sobre la Delincuencia Organizada Transnacional», firmada en Palermo (Italia) en diciembre de 2000 y a la que acompaña un Protocolo complementario para «prevenir, reprimir y sancionar la trata de personas especialmente las mujeres

\footnotetext{
${ }^{14}$ Página 64 del estudio de EDIS.

${ }^{15}$ Amo, ama s. m. y $f$.

1 Persona que tiene la propiedad de una cosa. En este caso, personas (mujeres).

2 Persona que tiene a otras que trabajan a su servicio. Obligadas o no.

3 Persona que tiene predominio o autoridad sobre los demás. Y lo ejerce a través de la fuerza: física, psicológica o como sea.
} 
y niños» y el que se formulan las definiciones en el artículo 3 de la siguiente manera:

"Para los fines del presente Protocolo:

a) Por «trata de personas» se entenderá la capacitación, el transporte, el traslado, la acogida o la recepción de personas, recurriendo a la amenaza o al uso de la fuerza u otras formas de coacción, al rapto, al fraude, al engaño, al abuso de poder o de una situación de vulnerabilidad o a la concesión o recepción de pagos o beneficios para obtener el consentimiento de una persona que tenga autoridad sobre otra, con fines de explotación. Esa explotación incluirá, como mínimo, la explotación de la prostitución ajena u otras formas de explotación sexual, los trabajos o servicios forzados, la esclavitud o las prácticas análogas a la esclavitud, la servidumbre o la extracción de órganos.

b) El consentimiento dado por la víctima de la trata de personas a toda forma de explotación intencional descrita en el apartado a) del presente artículo no se tendrá en cuenta cuando se haya recurrido a cualquiera de los medios enunciados en dicho apartado.

c) La captación, el transporte, el traslado, la acogida o la recepción de un niño con fines de explotación se considerará "trata de personas» incluso cunado no se recurra a ninguno de los medios enunciados en el apartado a) del presente artículo.

d) Por «niño o niña» se entenderá toda persona menor de 18 años."

El TSH con fines de explotación sexual hacia nuestro país, se considera desde la percepción de la Guardia Civil-, un problema de gran relevancia debido al incremento en los últimos años de la actividad de los grupos llamados "criminales organizados» ${ }^{16}$, y que son los que se dedican a la captación e introducción de mujeres inmigrantes que son explotadas en nuestro país de muy diversas formas.

Y como se manifiesta en el Informe de la Guardia Civil, haciendo referencia a los cambios en los negocios o de la industria alrededor del sexo, aprovechando y reconvirtiendo infraestructuras que ya existían, «se ha producido fundamentalmente a nivel de los Clubes de carretera, que han pasado de ser establecimientos pequeños a la categoría de auténticos complejos hoteleros (de lujo en algunos casos). Se ha estimado que el $80 \%$ de las mujeres que se prostituyen en nuestro país lo hacen en este tipo de establecimientos, estando situados la mayoría de ellos en demarcación competencia de la Guardia Civil. El otro $20 \%$ lo hace en pisos privados, en establecimientos urbanos tipo "sauna de masajes", en sus propias viviendas o como acompañantes de lujo y, en fin,

\footnotetext{
${ }^{16}$ Por «grupo organizado» entiende este Informe, la definición contemplada en el artículo 2 de la Convención de Naciones Unidas contra la Delincuencia Organizada Transnacional: «por grupo delictivo organizado se entenderá un grupo estructurado de tres o más personas que exista durante cierto tiempo y que actúe concertadamente con el propósito de cometer uno o más delitos graves o delitos tipificados con arreglo a la presente Convención con miras a obtener, directa o indirectamente, un beneficio económico u otro beneficio de orden material»».
} 
las personas más desfavorecidas, se prostituyen en la vía urbana y en zonas verdes, siendo estas modalidades más difíciles de controlan ${ }^{17}$.

Aunque algunas de las personas que ejercen prostitución en locales, como son los clubs, se pueden sentir «más seguras» y creen trabajar en mejores «condiciones laborales».

“- Trabajar en un club es más seguro. Yo lo prefiero. No pasas frío, no pasas hambre." [EP Colectivo: Mujer inmigrante -Brasil- que ejerce la prostitución en un local]

También hay que decir, que el ejercicio de la prostitución en sí mismo no es ilegal en nuestro país (no está penado), pero tampoco está claramente reconocido como actividad laboral.

En general, las mujeres que viajan a España para ejercer la prostitución contraen una deuda con las mafias, que les exigen el coste del viaje con intereses, un dinero que las mantiene bajo su yugo y que en ocasiones es tan elevada que la mujer jamás podrá pagarla. Éstas estarán entre 12 y 13 años ejerciendo prostitución para poder saldar ésta deuda.

Depende de la mafia que las capta pero también de su origen: para las hispanoamericanas oscila entre los 2.000 y 6.000 euros; las europeas entre 4.000 y 10.000 ; las asiáticas en torno a 20.000 y, las africanas 40.000 y 60.000 . "Cuanto más elevada sea la deuda, más rígido será el control ejercido sobre la persona prostituta", porque la mafia quiere recuperar su inversión por traer a la mujer a España y después cobrarse la deuda, y no duda en retenerlas, vejarlas y agredirlas para mantener su control. Incluso a algunas de estas mujeres, les tatúan un código de barras para dejar claro, quién es su dueño ${ }^{18}$ y cuál era su precio, por ejemplo, 2.000 euros.

Los beneficios económicos de este lucrativo negocio, rondan los 20.000 millones de euros. Negocio alrededor del sexo que tiene un lado oscuro en el que hay una gran cantidad de amenazas, entre prostituta y cliente, e incluso entre prostitutas. Más del $90 \%$ de las personas que ejercen prostitución, son inmigrantes ${ }^{19}$ procedentes de Sudamérica, del Este de Europa, y de África. Las africanas representan un $62 \%$ de las mujeres inmigrantes que ejercen prostitución, las europeas el $21 \%$ y las sudamericanas el $18 \%$. Un $85,3 \%$ son mujeres, un $13,9 \%$ son mujeres transexuales, y tan solo un $0,6 \%$ son varones lo que manifiesta, que la prostitución es mayoritariamente femenina (no hay datos oficiales ni censos de esta profesión, pero se calcula que entre 300.000 y 500.000 personas -mujeres- ejercen prostitución en nuestro país) y ligada a la inmigración.

\footnotetext{
${ }^{17}$ Estos datos han sido extraídos del Informe Criminológico: Tráfico de seres humanos con fines de explotación sexual, del Departamento de Análisis Criminal de la Unidad Técnica de Policía Judicial de la Guardia Civil. Años 2003 y 2004. Madrid. Página 7.

${ }^{18}$ Tal y como muestra en un Reportaje de "A Fondo" en Antena 3 TV de 2012.

${ }^{19}$ Las mujeres inmigrantes sufren una triple discriminación por su condición de: mujer, de prostituta y de extranjera. En muchos casos son víctimas del engaño y la explotación tanto en su itinerario migratorio como en el ejercicio de la actividad una vez alcanzados el destino.
} 
Por último, citar un dato esclarecedor y tremendo, y es que entre 2010 y 2011 fueron asesinadas 14 mujeres que ejercían prostitución ${ }^{20}$.

\section{Aspectos psicosociológicos del cliente de prostitución: el consumidor}

Este es otro de los actores invisibles (los consumidores de prostitución) del tema que estamos tratando, junto con las redes de explotación o las mafias. Es como si hubiera un acuerdo tácito sobre el ocultar o silenciar el espacio, lugar o rol que ocupan los clientes en el mundo de la prostitución. Pero lo que está claro, es que si existe la prostitución (oferta), es porque existen demandantesclientes. Y por los pocos estudios existentes, a los clientes les cuesta mucho aceptar su condición, representarse socialmente como tales (consumidores), es decir, no se autoreconocen.

Lo primero que hay que decir, es que no existe un perfil tipo del cliente. El perfil sociológico de personas que acuden a los servicios sexuales de una mujer prostituta es muy variado: intelectuales; estudiantes; con escaso nivel de estudios; solteros, casados; prácticamente, de todas las edades y nacionalidades; a algunos les gusta acudir asiduamente todas las semanas a solicitar servicios a una prostituta, otros sólo van de manera esporádica; puede haber preferencias por el medio abierto (calle) o bien preferir un local cerrado (clubes). La heterogeneidad es tan grande que no cabe hablar de un perfil tipo del cliente de la prostitución.

El cliente de la nueva prostitución es cada vez más joven. Mayor oferta en la última década debido a la explotación sexual de la inmigración. La cultura de la inmediatez, la voluntad de obtener de forma rápida y sin esfuerzo el sexo sin compromiso, han sido factores clave para este cambio de perfil en una generación que, paradójicamente, ha nacido después de la revolución sexual. Despedidas de soltero; celebraciones deportivas; cenas de empresa; cumpleaños o mayorías de edad. Finalizar una noche de juerga o desahogo rápido tras una jornada de trabajo: los motivos para acudir a los servicios de las mujeres prostitutas, son tantos como los clientes. Pero el denominador común aparece cada vez más claro: cuanto más rejuvenece la clientela, más aumenta la visión de la prostitución como parte integrante de la oferta de ocio. El perfil del cliente masculino de la prostitución en España es sensiblemente más joven que hace 10 años.

Según los estudios de la Asociación para la Prevención, Reinserción y Atención de la Mujer Prostituida (APRAMP), el cliente habitual era en 1998 un varón casado y con cargas familiares, mayor de 40 años. En 2005 abundaban los jóvenes de 20 a 40. Es decir, con una media de edad de 30 años. Según el INE, el $27 \%$ de los varones españoles de 18 a 49 años reconoce haber recurrido alguna vez a los servicios de una prostituta.

En algunas de las principales ciudades españolas, se han llevado a cabo campañas publicitarias para "criminalizar el consumo de prostitución". En el

\footnotetext{
${ }^{20}$ Feminicidio por prostitución, es un crimen que se comete con frecuencia en las sociedades patriarcales.
} 
año 2004, y siendo por aquel entonces alcalde de Madrid, Alberto RuizGallardón, llegó Ana Botella (actual alcaldesa de Madrid), y asumió Servicios Sociales. Su equipo diseñó un Plan contra la Esclavitud Sexual que tenía dos partes diferenciadas y dos líneas de actuación: la primera consistía en el hostigamiento policial en la calle, especialmente en la calle Montera (muy cerca de la Puerta de Sol y muy transitada por la ciudadanía) y, lo hicieron con el registro de los clientes $u$ hombres que la transitaban; el control de las pensiones; videovigilancia (cámara), y con cortes de tráfico en otras zonas de Madrid donde se ejercía la prostitución.

El segundo Plan de Acción, consistió en el desarrollo de una campaña de propaganda contra la prostitución, con unos carteles publicitarios, por ejemplo, que rezaban: «Porque tú pagas, existe la prostitución. No contribuyas a perpetuar la explotación de seres humanos». Culpabilizando, una vez más, a los ciudadanos (varones principalmente) mediante una campaña que pagamos con las arcas del municipio (es decir, con el dinero de la ciudadanía).

Pocos meses después, el Ayuntamiento de la capital nos volvió a sorprendió con una nueva campaña publicitaria impactante. En esta ocasión, empapelando la red del metro de Madrid y las marquesinas de los autobuses: «No contribuyas a perpetuar la prostitución. No compres servicios sexuales. Recuerda que con tu dinero estás haciendo mucho daño a alguien», decía uno de los letreros de esa nueva campaña que vinculaba prostitución a tráfico de armas y a la explotación de mujeres.

\section{Alternativas al mercado del sexo}

Las mujeres que deciden dejar de ejercer prostitución, tienen una salida objetiva y eficaz y es participar en programas de inserción sociolaboral ${ }^{21}$. Donde podrán recuperar ciertas habilidades sociolaborales, y que con el ejercicio continuado durante largo tiempo, han perdido, como son:

- Cumplimientos de horarios.

- Aceptación de potenciales salarios bajos.

- Adaptación a compañeros y compañeras, jefes y superiores.

- Asunción de responsabilidades.

- Apoyo en su motivación y refuerzos personales.

- Capacidad de trabajo en equipo.

"- Situaciones de mucha inseguridad y de mucho estrés pues que les lleva a que gente muy capacitada y con una serie de habilidades cuando llega a una entrevista tenga la sensación de que la persona que está enfrente la conoce sabe que ha ejercido prostitución la pueda reconocer y eso son bloqueos, ahí

\footnotetext{
${ }^{21}$ Aunque con las reducciones que está llevando el actual Gobierno de España y por ende, el de la Comunidad de Madrid en el tema de las políticas activas de empleo (cierre de los Centros Integrados de Empleo; OPEAS; SIL..... y del despido de personal contratado para trabajar en las Oficinas de la Dirección General de Empleo de la C. Madrid), no quedarán programas de inserción sociolaboral para ayudar a las personas que decidan salir de la prostitución. Se "cargan" los programas de itinerarios sociolaborales que funcionaban hasta ahora.
} 
hay un trabajo muy serio en cuanto a recuperación de hábitos, de echo uno de los objetivos más básicos en nuestros talleres de formación es que recuperen esos hábitos mínimos, de horarios, de responsabilidad en el trabajo de que cuiden la tarea... Entonces aunque después aprendan un oficio que pueda favorecer su salida al mercado laboral o no, lo que sí pretendemos es eso, que cumplan un horario, que tengan una responsabilidad, que cuando una persona falta, cómo tiene que dirigirse al responsable inmediato, que sea capaz de trabajar en equipo, una serie de cosas que por el ejercicio de la prostitución nunca a vivido". [EP Profesionales de inserción sociolaboral: Mujer que ejercen prostitución]

Cuando deciden dejar la actividad, lo primero que necesitan es:

o Asesoría jurídica. Porque muchas de las personas que han ejercido la prostitución suelen tener problemas con la justicia, además, de encontrarse en situación de irregularidad -sobre todo las mujeres inmigrantes- $y$;

o Buscar y lograr un empleo. Como el medio de lograr y vertebrar el cambio y la salida de la prostitución.

"- Si es al tema de asesoría jurídica se canaliza la demanda y si es al tema de búsqueda de empleo es cuando iniciamos todo el proceso de análisis curricular, de ver realmente cuales son sus expectativas, de ver cuales son sus necesidades y hasta donde vamos a poder llegar con esa persona". [EP Profesionales de inserción sociolaboral: Mujer que ejercen prostitución]

o Formación y cualificación ${ }^{22}$. Porque muchas de estas personas no han tenido experiencia laboral y por tanto, carecen de currículum.

"- A partir de ahí, sí. Se le ofrecen los proyectos de formación, una por trabajar toda esa serie de habilidades sociales y otra porque la permanencia en esos talleres de formación nos permite ir elaborando ese itinerario individualizado y hacer esos seguimientos cosa bastante difícil si funcionamos con citas. Es decir nosotros lo que tenemos muy claro es que dar una cita a una persona muchas veces lo que significa es que no viene, que se pierde el caso, que se queda ahí y que a lo mejor hasta dentro de 6 meses esa persona que vuelve a tener otra demanda no viene". [EP Profesionales de inserción sociolaboral: Mujer que ejercen prostitución]

En general tienen altas dificultades a la hora de buscar un puesto de trabajo, dado que el paro afecta mayoritariamente a las mujeres. Éstas deben «ocultan» en las entrevistas su pasado por el ejercicio de esta actividad.

\footnotetext{
${ }^{22}$ Según los profesionales en inserción sociolaboral entrevistados, afirman que a la hora de formarse las personas que deciden dejar la prostitución, se encuentran con el problema de reducir su nivel de ingresos económicos, ya que el número de horas dedicadas a la formación suele ser elevado. Y esta dificultad en el mantenimiento de la formación, hace sea necesaria pagarla (conciliación de la formación con el ejercicio de la prostitución). Otro problema es el poder mantener la conciliación familiar, la formación y el ejercicio de la prostitución, sobre todo cuando ellas tienen cargas familiares.
} 


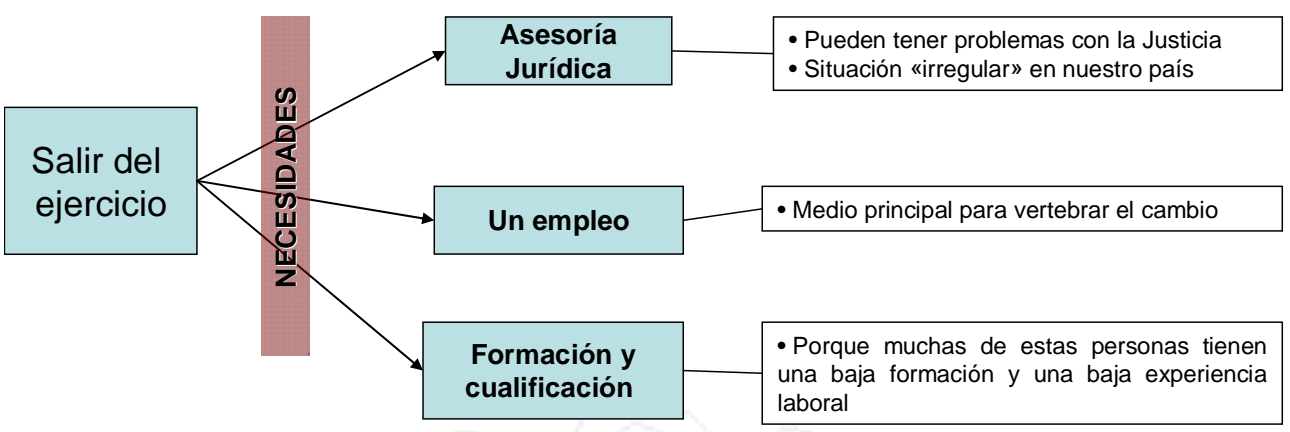

\section{Conclusiones}

Es un fenómeno complejo y que afecta a una realidad que tiene múltiples esferas y por tanto, es imposible contar con una única perspectiva. Y siempre está rodeado de polémica social, jurídica, moral, psicológica....

Esta actividad o ejercicio tiene muchos "claroscuros", tanto en las reacciones sociales hacia ella, como hacia las personas que se dedican a esta profesión (a través de su estigmatización).

La prostitución es una práctica/ejercicio/actividad laboral "sumergida", es decir, sin estar regulada; sin contrato; sin derechos; dentro del trabajo sumergido; sin legislación laboral....

Una parte significativa de las mujeres que la están ejerciendo -en nuestro paísson extranjeras, y muchas "sin papeles". Sin duda, su condición de personas extranjeras irregulares, así como la necesidad de hacer frente a las deudas contraídas y, con mucha frecuencia, a las necesidades de sus familias en sus países de origen, las hacen ser especialmente vulnerables. Una parte significativa de las mujeres tanto migrantes como las autóctonas optan por la prostitución porque les permite obtener ingresos muy superiores a los que lograrían en las actividades ordinarias o normalizadas. Por sus características, la prostitución es compatible con otras actividades laborales o un recurso temporal para hacer frente a la pérdida del trabajo. Sin duda, a pesar de los altos ingresos (según quien lo cuente/relate), el ejercicio de la prostitución no resulta una actividad fácil para nadie.

Porque a la dureza en las condiciones objetivas y de la exposición a riesgos ${ }^{23}$ de todo tipo (agresiones y/o violencia física; deudas económicas; sanitarias; legales; etcétera), hay que añadir que se trata de una actividad objeto de un

\footnotetext{
${ }^{23}$ Riesgos como los malos tratos, los contagios de enfermedades infecciosas, el SIDA y otras, como los embarazos no deseados y las secuelas físicas, son los riesgos más destacables del ejercicio de esta actividad laboral.
} 
fuerte rechazo social (altamente estigmatizada), lo que obliga a las mujeres a mantenerla oculta o a enfrentar el rechazo (cierta esquizofrenia), requiriendo de un esfuerzo suplementario para elaborar subjetivamente el estigma.

Y los demandantes de la prostitución, es decir, los consumidores son los actores invisibles/fantasmas de esta "película/realidad sociolaboral" que tantos ingresos genera y de forma sumergida. Además, no hay un perfil tipo de consumidor, sino que se puede decir, que hay tantos perfiles como casi clientes. Depende en muchos casos de su propia fuente/disponibilidad de ingresos económicos para poder consumir servicios sexuales. Pero una cosa está clara, el cliente de la nueva prostitución es cada vez más joven que hace 15 años. Por otro lado, a través de determinadas campañas de sensibilización municipales, se ha tratado de criminalizar este consumo (si estrangulan la afluencia de los consumidores, podría bajar la oferta). Pero a pesar de estas intenciones y políticas represivas llevadas a cabo en determinados municipios españoles, el ejercicio/actividad no se ha reducido (ni por ende su consumo). Por tanto, seguimos sin darle solución a un problema tan importante como es éste, ni se termina de prohibir, ni se legaliza, tan solo lo ocultamos, "lo sumergimos" más. Y mientras, los únicos beneficiarios de toda esta pasividad social y política -las redes y mafias- siguen ganando y haciendo caja. 